\title{
Family cluster of asymptomatic infections with COVID-19: a case series of 4 patients
}

\author{
Lingbo Deng ${ }^{1}$, Ling Ji ${ }^{2}$, Zuowei Meng ${ }^{3}$, Yungen Gan ${ }^{4}$, Guanxun Cheng ${ }^{1}$ \\ ${ }^{1}$ Department of Medical Imaging, ${ }^{2}$ Department of Clinical Laboratory, ${ }^{3}$ Outpatient Service Office, Peking University Shenzhen Hospital, Shenzhen \\ 518036, China; ${ }^{4}$ Department of Radiology, Shenzhen Children's Hospital, Shenzhen 518035, China
}

Correspondence to: Guanxun Cheng. Department of Medical Imaging, Peking University Shenzhen Hospital, Shenzhen 518036, China. Email: 18903015678@189.cn.

Submitted Mar 04, 2020. Accepted for publication Apr 01, 2020.

doi: 10.21037/qims.2020.04.15

View this article at: http://dx.doi.org/10.21037/qims.2020.04.15

\section{Introduction}

In December 2019, several cases of "unknown viral pneumonia" were reported in Wuhan City, Hubei Province, China (1). It was named as the 2019 novel coronavirus disease (COVID-19) by the World Health Organization (WHO) (1). In just two months, the virus has spread from Wuhan to other parts of China, and all over the world. By 24:00 on March 8, accumulative 80,735 confirmed cases with 5,111 severe cases, 58,600 cured cases, and 3,119 deaths were documented in China (2). Accumulative 29,215 confirmed cases, 3,343 cured cases and 707 deaths were documented in countries outside of China (3). With the development of the epidemic, the clustered cases were found (4). The incubation period of COVID-19 is generally 3 to 7 days. COVID-19 is also highly contagious in the incubation period (5). The main clinical manifestations are fever, fatigue, dry cough, dyspnea, with or without nasal obstruction, runny nose, and other upper respiratory symptoms. There are also asymptomatic infections (6). Asymptomatic infections make the prevention and control of COVID-19 even harder. This paper reports the discovery process of 4 cases of asymptomatic infected people with familial cluster.

\section{Case presentation}

\section{The discovery process of the cases}

The patient (case 1) came from Wuhan to Shenzhen by train at 9:00 on January 21, 2020, and stayed at room relatively 'isolated' after he got to his son's (case 2) home. He measured temperature every day, and had no respiratory symptoms such as fever and cough. His daughter-inlaw (case 3) worked in a hospital. On February 9, 2020, at the request of the hospital, his son and daughter-inlaw underwent chest CT screening in the department of medical imaging of Peking University Shenzhen Hospital, Shenzhen, China. The chest CT of his son was highly suggestive of COVID-19 pneumonia, while his daughterin-law's chest CT had no manifestation of COVID-19 pneumonia.

Case1 was immediately notified to undergo a chest CT examination. His chest CT was also highly suggestive of COVID-19 pneumonia. The patient, his son, and his daughter-in-law carried out the reverse transcriptionpolymerase chain reaction (RT-PCR) for throat swab samples on the same day.

On February 10, 2020, the patient's wife (case 4) and his older granddaughter (case 5) were asked for a chest CT examination. Their CT findings were highly suspicious of COVID-19 pneumonia. On the same day, the RTPCR for throat swab samples was detected. His younger granddaughter (case 6) went to Shenzhen children's hospital for chest CT examination without abnormality, and the RTPCR for throat swab samples was performed.

The results of RT-PCR about the patient, his wife, his son, and his granddaughter were all positive. They were immediately transferred to the designated hospital for treatment. The results of RT-PCR about his daughter-inlaw and little granddaughter were negative and asked to be 


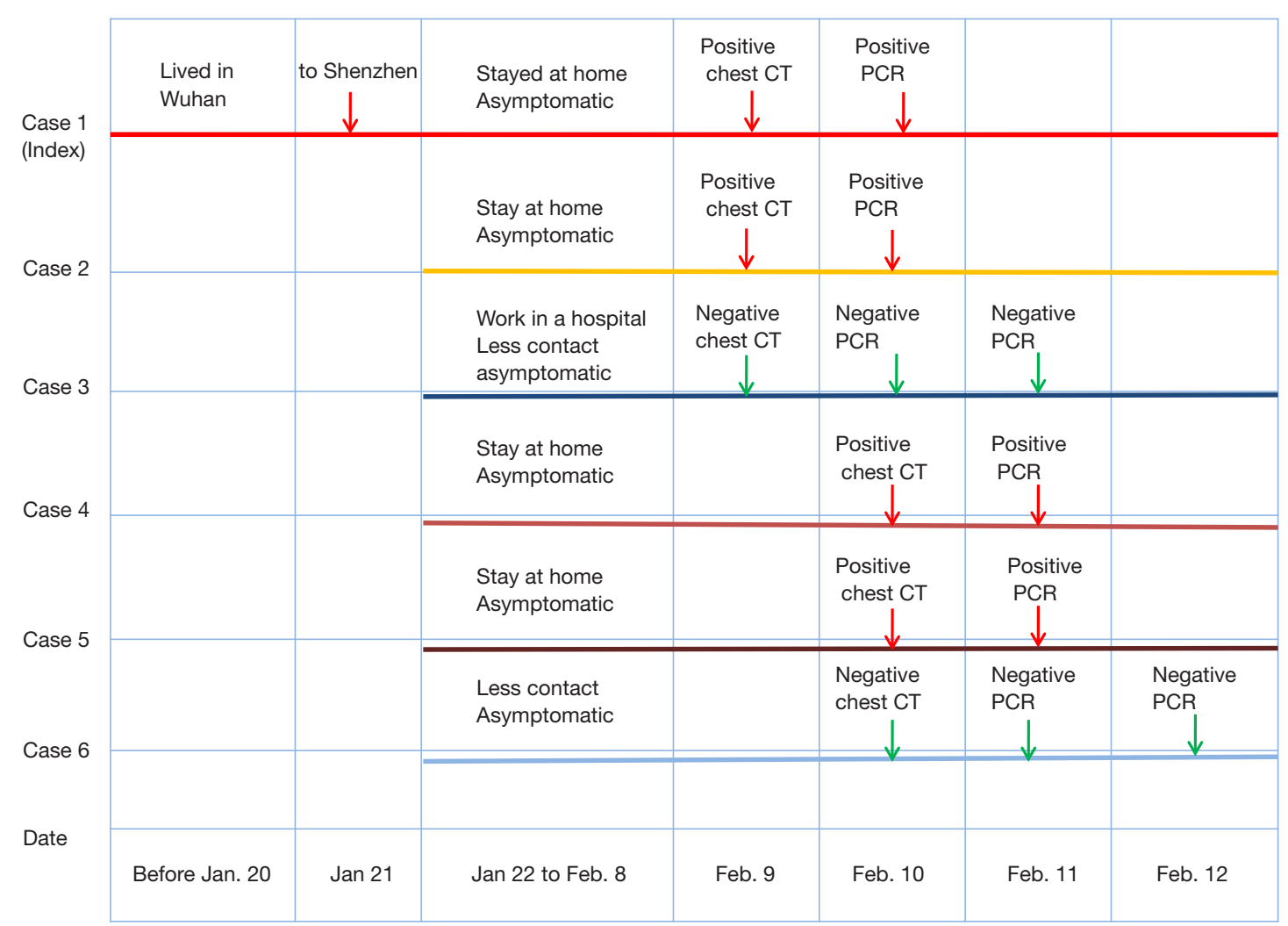

Figure 1 Timeline of family cluster of asymptomatic infections with COVID-19.

isolated at home (Figure 1).

Centers for Disease Control and Prevention(CDC) and the streets where these cases it is located were asked to take more strict prevention, control and isolation measures and medical observation for those who may had contact with the family members and the environment, and no new suspected case has been found until March 8 .

\section{Chest CT findings of the cases}

Case 1, male, 69 years old. Normal white blood cell count, lymphocyte count and C-reactive protein. Chest CT showed the upper and lower lobes of the right lung scattered small, thin, ground-glass opacity with unclear boundary. Multiple linear shadows were seen in the right lung, and the lesion range was less than $10 \%$. According to the literature report $(7,8)$, the image manifestations of the lesion were in the dissipation period (Figure 2).

Case 2, male, 49 years old, white blood cell and lymphocyte count and C-reactive protein were normal. Chest CT showed that the lower lobes of both lungs had scattered patchy ground-glass opacity with unclear boundary. A few linear shadows were seen in the lower lobes, and the lesion range was about $10 \%$. According to the literature report, the image manifestation of the lesion belonged to the dissipation period (Figure 3).

Case 3, female, 49 years old. Normal white blood cell and lymphocyte count, normal C-reactive protein. No viral pneumonia on chest CT (Figure 4).

Case 4, female, 69 years old. Normal leukocyte and lymphocyte count as well as normal C-reactive protein. Chest CT showed that bilateral lung mottled groundglass opacity with unclear boundary and multiple linear shadows. The lesion range was about $15 \%$. According to the literature report, the image manifestation of the lesion belonged to the dissipation period (Figure 5).

Case 5, female, 16 years old. Normal white blood cell and lymphocyte count, and normal C-reactive protein. Chest CT showed typical paving stone like changes with limited scattered high-density shadows in the sub pleural of the lower lobe of both lungs, accompanied by the thickening of the interlobular septum. According to the literature report, 

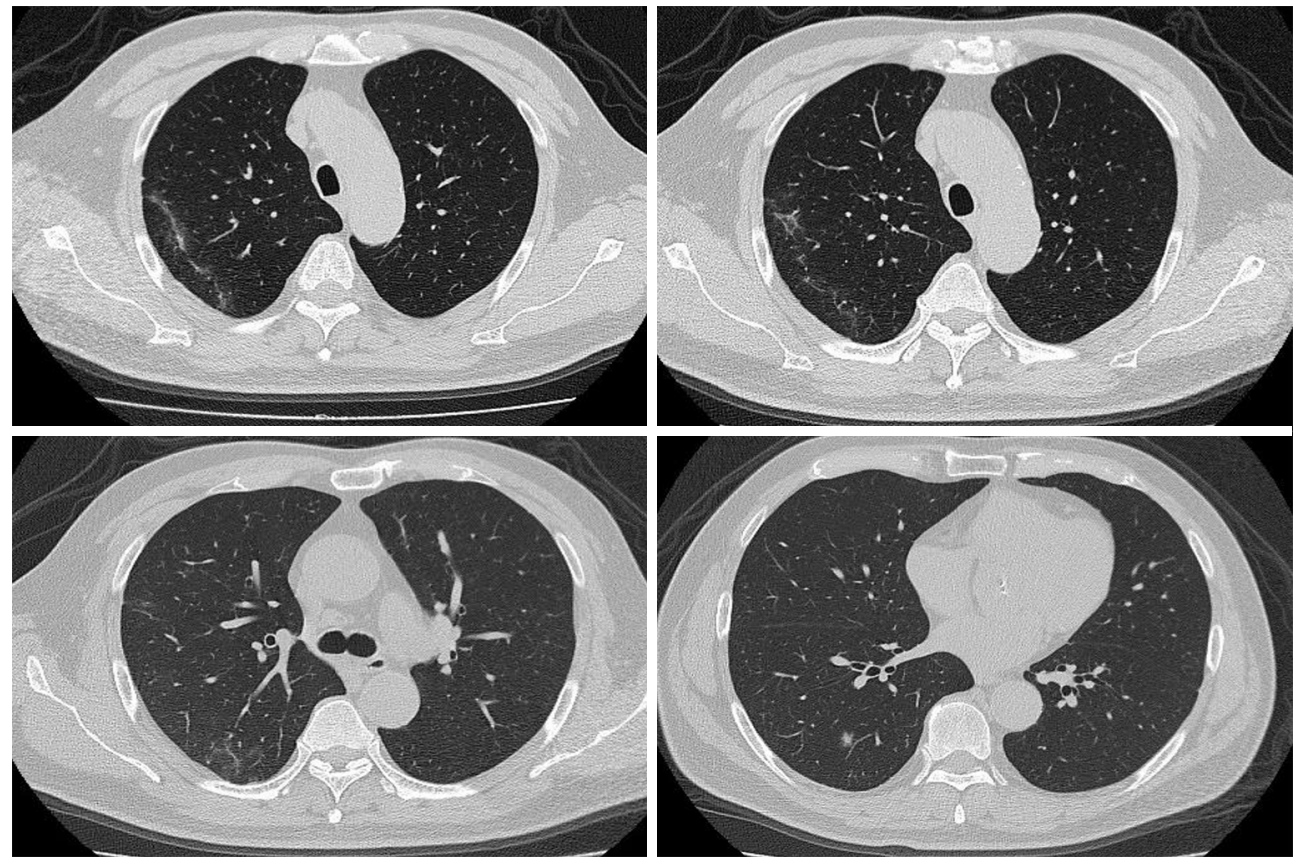

Figure 2 Case 1, a 69-year-old male, upper and lower lobes of the right lung show scattered small thin ground-glass opacity, unclear boundary, and multiple small linear shadows.

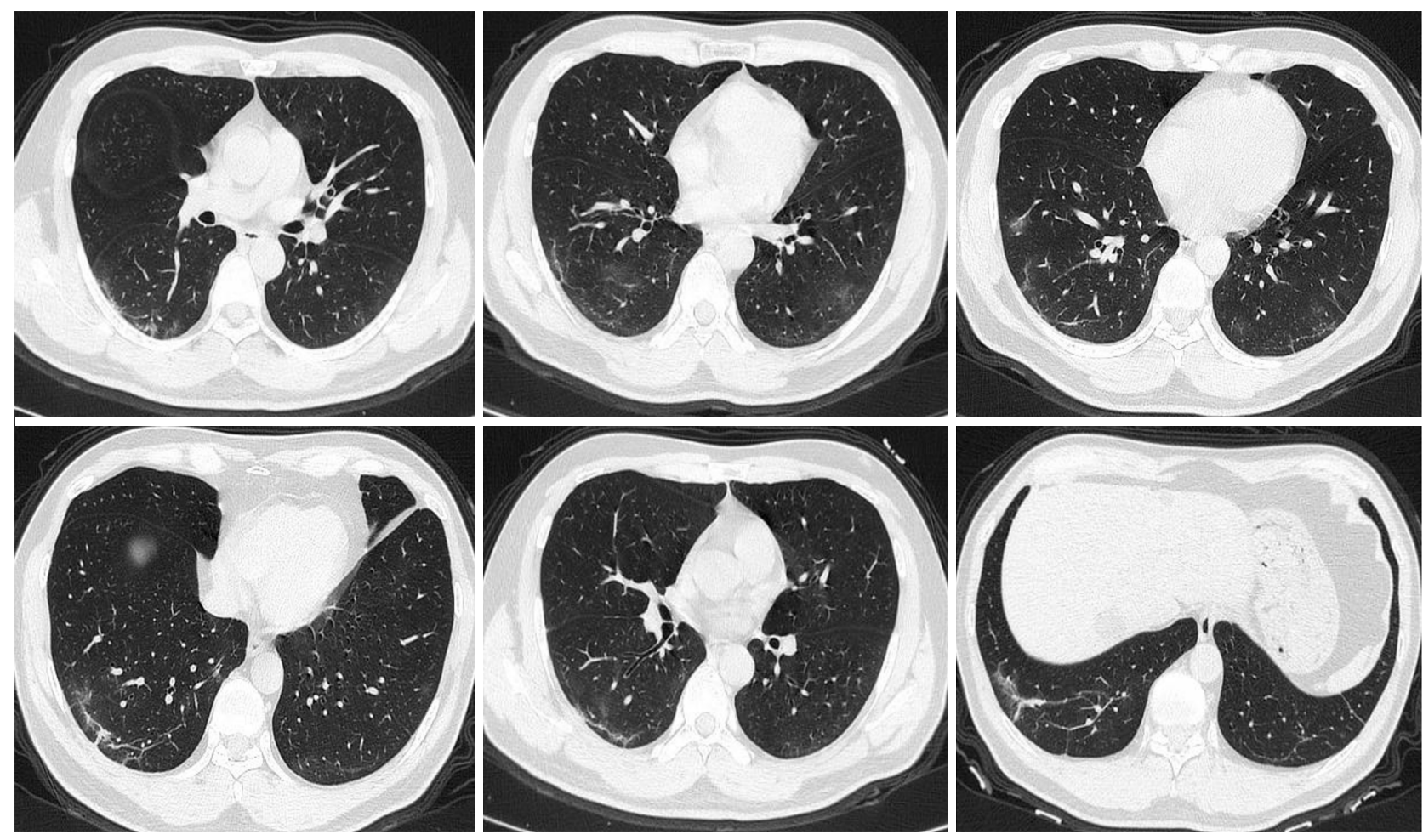

Figure 3 Case 2, a 49 years old male, CT shows patchy ground-glass opacity in the lower lobes of both lungs, with unclear boundary and multiple linear shadows. 

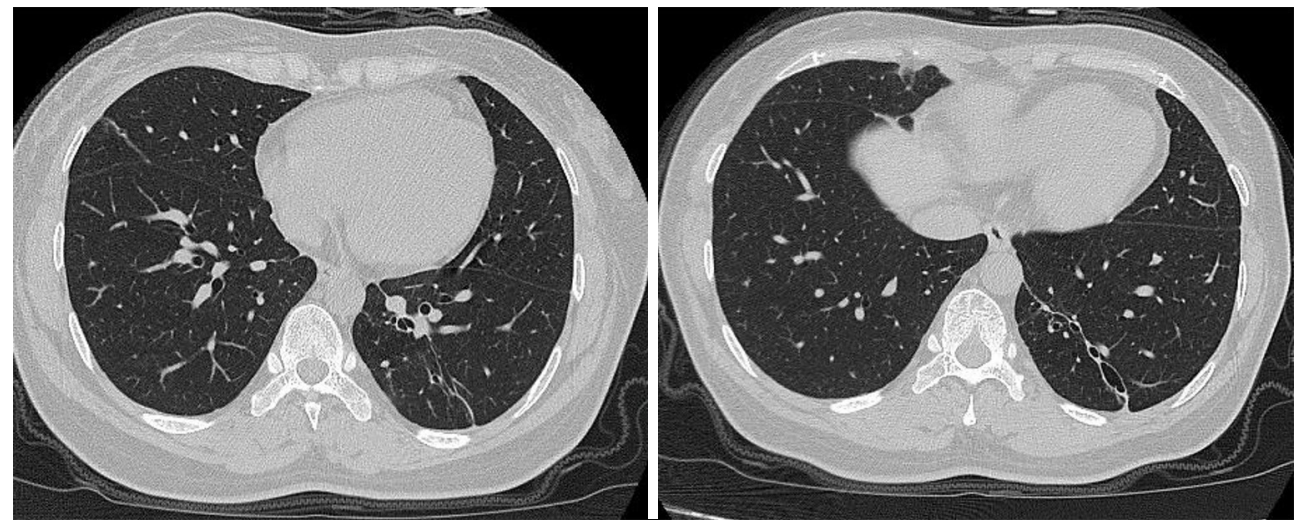

Figure 4 Case 3, a 49 years old female, chest CT shows bronchiectasis with linear shadow around at right middle lobe and left lower lobe of the lung. No viral pneumonia.

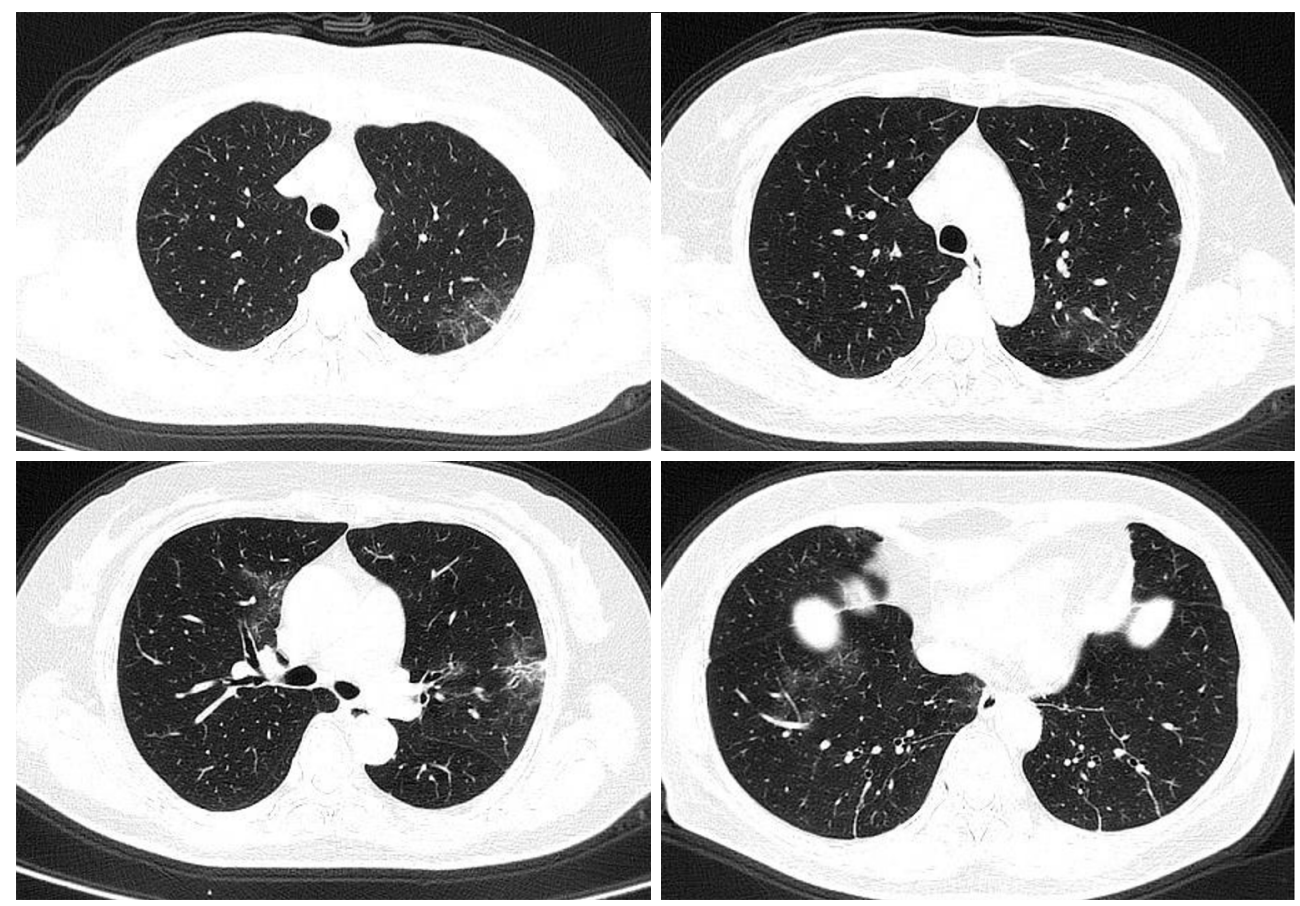

Figure 5 Case 4, a 69 years old female, chest CT shows that bilateral lungs mottled ground-glass opacity with unclear boundary and multiple linear shadows.

the imaging manifestation of this case belonged to the consolidation stage (Figure 6).

Case 6, female, 2 years old. No abnormality found on chest CT (Figure 7).

\section{Discussion}

This is a report of a group of asymptomatic infections with family aggregation. Case 1 came from Wuhan. He has been relatively 'isolated' for 20 days at home without clinical symptoms. As the local disease prevention and control policy request, the chest $\mathrm{CT}$ of his son was first conducted and revealed findings consistent with COVID pneumonia. Isolation measures were immediately taken, his family members were asked to take chest CT and RT-PCR testing. The chest CT manifestations of 4 infected patients were 

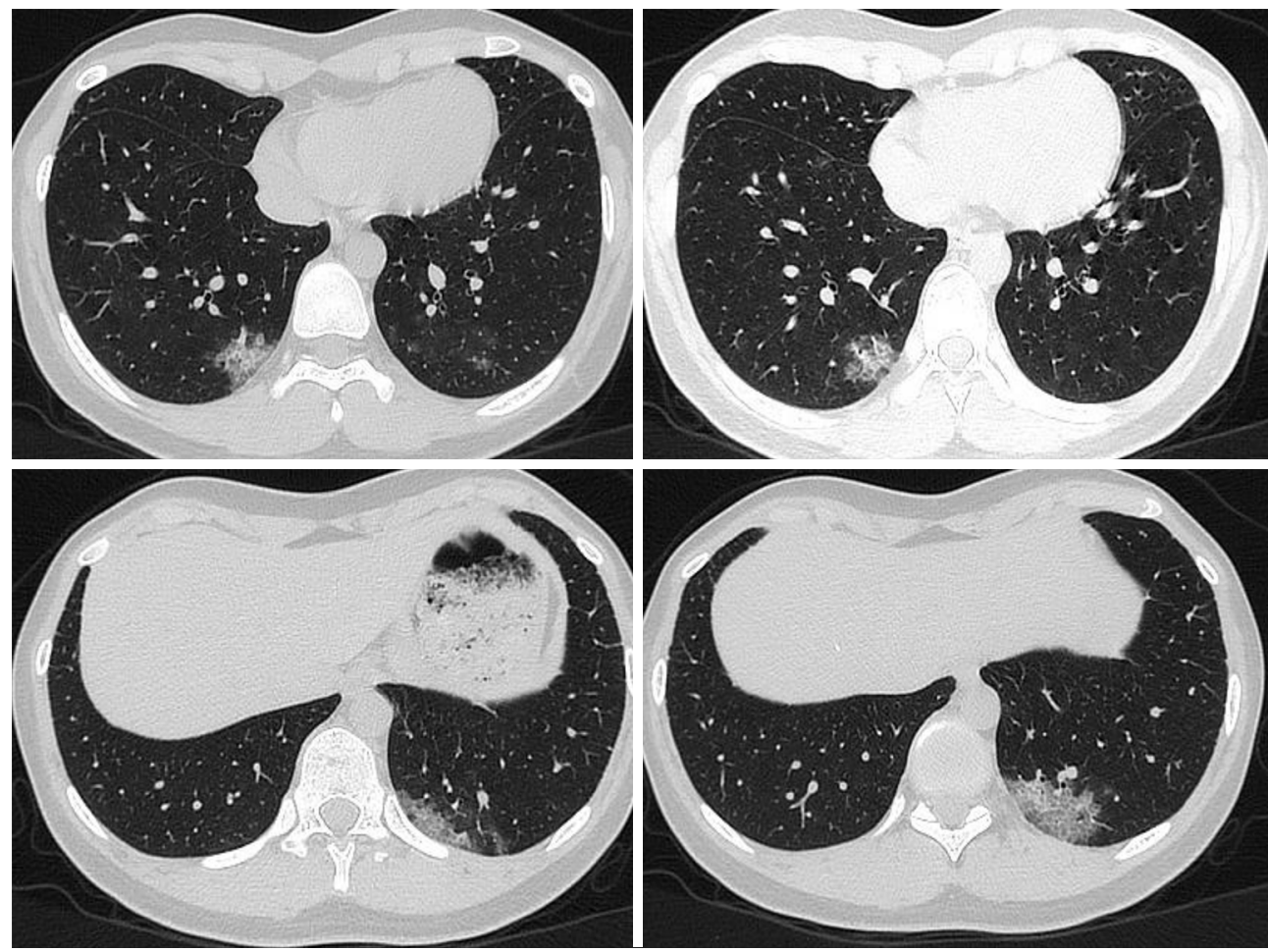

Figure 6 Case 5, a 16 years old female, chest CT shows patchy density under the pleura of the lower lobes of both lungs, showing typical paving stone like change. Thickening of interlobular septa is also noted.
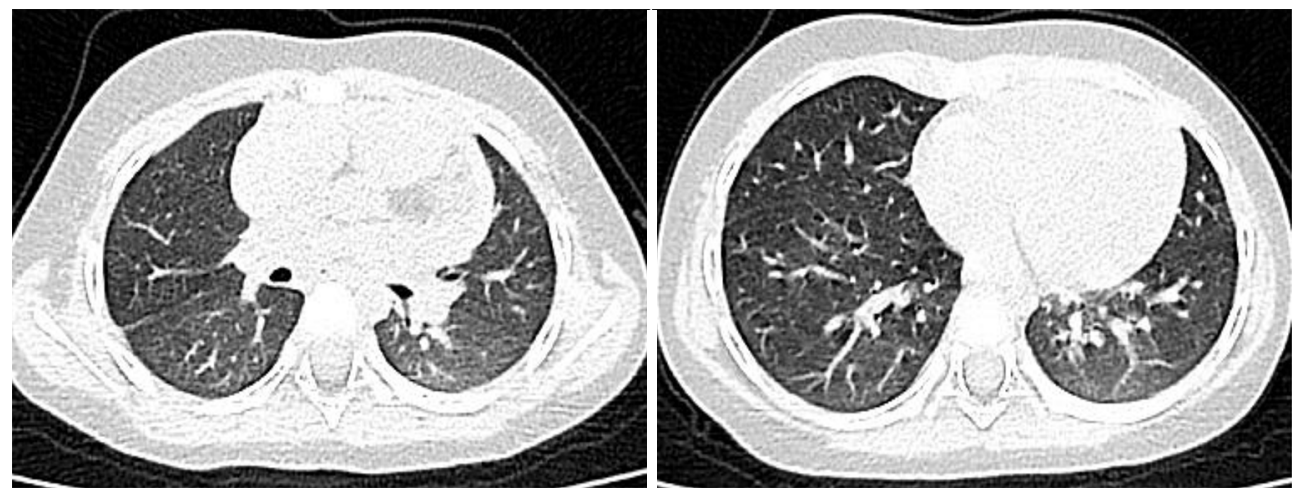

Figure 7 Case 6, a 2 years old girl, no abnormality on chest CT.

different in this group, which may be due to the different timings of virus infection and different responses of the body to the virus. In case 1 , the lung lesions were small in size, low in density, and fibrosis was seen. The inflammation in the lung was in the dissipation and absorption stage. This patient might be the first one who had contact with the virus. In case 5 , the density of lung lesions was relatively high, and it was in the consolidation stage. It may be due to the shorter exposure time of viruses and the different immunity of the body to the virus for this case. This case series highlights the importance of proactive measures to identify COVID-19 infection among asymptomatic subjects with exposure history.

\section{Acknowledgments}

Funding: None. 


\section{Footnote}

Conflicts of Interest: All authors have completed the ICMJE uniform disclosure form (available at http://dx.doi. org/10.21037/qims.2020.04.15). The authors have no conflicts of interest to declare.

Informed Consent: Written informed consent was obtained from the patient for publication of this study and any accompanying images.

Open Access Statement: This is an Open Access article distributed in accordance with the Creative Commons Attribution-NonCommercial-NoDerivs 4.0 International License (CC BY-NC-ND 4.0), which permits the noncommercial replication and distribution of the article with the strict proviso that no changes or edits are made and the original work is properly cited (including links to both the formal publication through the relevant DOI and the license). See: https://creativecommons.org/licenses/by-nc-nd/4.0/.

\section{References}

1. General Office of National Health Committee. Office of State Administration of Traditional Chinese Medicine. Notice on the issuance of a programmers for the diagnosis and treatment of novel coronavirus $(2019-\mathrm{nCoV})$ infected pneumonia (trial sixth edition)]. Available online: http:// www.nhc.gov.cn/yzygj/s7653p/202002/3b09b894ac9b4204 a79db5b8912d4440.shtml

2. General Office of National Health Committee. Office of State Administration of Traditional Chinese Medicine. New Coronavirus Pneumonia Epidemic Prevention and Control, Update on the epidemic situation of new coronavirus pneumonia by 24:00 on March 8 . Available online: http://www.nhc.gov.cn/xcs/yqfkdt/202003/f2c83db 9f73d4be5be0dc96af731813c.shtml

3. New crown pneumonia real-time outbreak tracking. Overseas epidemic by 24:00 on March 8 .

Cite this article as: Deng L, Ji L, Meng Z, Gan Y, Cheng G. Family cluster of asymptomatic infections with COVID-19: a case series of 4 patients. Quant Imaging Med Surg 2020;10(5):11271132. doi: 10.21037 /qims.2020.04.15
Available online: https://www.360kuai.com/mob/ subject $/ 400$ ?sign $=360 \_6 a a 05217$

4. Chan JF, Yuan SF, Kok KH, To KK, Chu H, Yang J, Xing FF, Liu JL, Yip CC, Poon WS, Tsoi HW, Lo SK, Chan KH, Poon VK, Chan MW, Ip JD, Cai JP, Cheng VC, Chen HL, HuiCK, Yuen KY. A familial cluster of pneumonia associated with the 2019 novel coronavirus indicating person-to-person transmission: a study of a family cluster. Lancet 2020;395:514-23.

5. Guan HX, Xiong Y, Shen NQ, Fan YQ, Shao JB, Li HJ, Li XM, Hu YD, Zhu WZ, Jin ZY. 2019 novel coronavirus (2019-nCoV) pneumonia clinical imaging characteristics. Radiol Pract 2020. DOI: 10.13609/ j.cnki.1000-0313.2020.02.001.

6. Xu R, Du MS, Li LF, Zhen ZM, Wang HY, Hu XF. CT imaging of one extended family cluster of corona virus disease 2019 (COVID-19) including adolescent patients and "silent infection". Quant Imaging Med Surg 2020;10:800-4.

7. Wang WG, Hu H, Song L, Gong XM, Qu YJ, Lu YZ. Image of pulmonary and diagnosis of atypical novel coronavirus (2019-nCoV) infected pneumonia: case series of 14 patients. New Med 2020;30:7-9.

8. Jin YH, Cai L, Cheng ZS, Cheng H, Deng T, Fan YP, Fang C, Huang D, Huang LQ, Huang Q, Han Y, Hu B, Hu F, Li BH, Li YR, Liang K, Lin LK, Luo LS, Ma J, Ma LL, Peng ZY, Pan YB, Pan ZY, Ren XQ, Sun HM, Wang Y, Wang YY, Weng H, Wei CJ, Wu DF, Xia J, Xiong Y, Xu HB, Yao XM, Yuan YF, Zhang XC, Zhang YW, Zhang YG, Zhang HM, Zhao Y, Zhao MJ, Zi H, Zeng XT, Wang YY, Wang XH, for the Zhongnan Hospital of Wuhan University Novel Coronavirus Management and Research Team, Evidence-Based Medicine Chapter of China International Exchange and Promotive Association for Medical and Health Care (CPAM). A rapid advice guideline for the diagnosis and treatment of 2019 novel coronavirus (2019-nCoV) infected pneumonia (Standard version), Mil Med Res 2020;7:4. 